\title{
Estudo das Preferências de Alunos e Professores sobre Videoaula para Identificar Requisitos de Software para Ferramentas de Produção
}

\author{
Solange F. L. Medeiros, Luciano T. E. Pansanato \\ Universidade Tecnológica Federal do Paraná (UTFPR) \\ Cornélio Procópio - PR - Brazil \\ solange@uenp.edu.br, luciano@utfpr.edu.br
}

\begin{abstract}
The objective of this work was to study preferences of students and teachers regarding video lectures to identify requirements for production tools. A survey methodology was used and the questionnaire technique was used for data collection. Different for students and teachers, the questionnaire was sent to participants of technical courses. The main results indicate the similarities and differences in the preferences of students and teachers, respectively, for the video lecture use and video lecture production. Requirements for the project of production tools are presented at the end which were defined based on the results.
\end{abstract}

Resumo. O objetivo deste trabalho foi estudar as preferências de alunos e professores com relação à videoaula para identificar requisitos para ferramentas de produção. O método utilizado foi o de levantamento e a técnica de questionário foi utilizada para a coleta de dados. O questionário, diferente para alunos e professores, foi enviado para participantes de cursos técnicos. Os principais resultados indicam as semelhanças e diferenças nas preferências de alunos e professores, respectivamente, para o uso e produção de videoaula. Ao final são apresentados requisitos para o projeto de ferramentas de produção de videoaula definidos com base nos resultados.

\section{Introdução}

O avanço da Tecnologia de Informação e Comunicação (TIC) proporciona alternativas para alunos e professores. A videoaula é uma tecnologia que desempenha função didática, na qual as informações transmitidas podem ser ouvidas e visualizadas facilitando a compreensão (Barrére et al. 2011). Existem vários estilos de videoaula e o estilo mais comum é a filmagem da aula tradicional e a sua disponibilização em um formato de vídeo digital. No entanto, esse estilo apenas reproduz o ensino tradicional e está limitado aos recursos geralmente empregados em sala de aula.

A produção de videoaula é mais difícil do que criar materiais impressos, pois envolve competências especiais não somente de produção, mas também de engenharia. O tempo empregado na preparação de videoaulas é consideravelmente grande. Além disso, a inexperiência do professor com as ferramentas de produção faz com que o tempo dedicado no desenvolvimento aumente e se torne um aspecto negativo na sua utilização (Chandra 2011). 
O estilo de apresentação da videoaula varia de um vídeo simples da sala de aula até um vídeo com autoria altamente elaborada que inclui closes e cortes de professores, slides, desenhos e animações interativas (Ilioudi et al. 2013). Embora o uso de videoaulas esteja crescendo, existem poucos estudos com relação a estilos de videoaula (Keengwe 2007; Cross et. al. 2013; Dotta et. al. 2013).

Neste trabalho é apresentado um estudo das preferências de alunos e professores com relação à videoaula e seus estilos. O objetivo principal é identificar requisitos de software para ferramentas mais específicas para a produção de videoaula. Adicionalmente, também é objetivo (secundário) identificar necessidades para um programa de treinamento de professores na produção de videoaulas. O grupo de respondentes selecionado para este estudo é composto por alunos e professores de cursos técnicos (subsequentes ao ensino médio) oferecidos na modalidade à distância no âmbito do e-Tec Brasil.

\section{Trabalhos relacionados}

Os trabalhos de Guo et al. (2014), Cross et al. (2013), Dotta et al. (2013), Ilioudi et al. (2013), Vieira et al. (2014) e Brecht (2012) apresentam pesquisas relacionadas a estilos, preferências, uso e produção de videoaula. Raabe et al. (2014) apresentam um estudo de caso de produção e avaliação de videoaulas para ensino de programação, mas o estilo utilizado foi a gravação de três formatos de aula tradicional com pequenas variações relacionadas à forma de apresentação do conteúdo e interação com um software.

Guo et al. (2014) tiveram como objetivo identificar quais estilos de videoaula levam aos melhores resultados de aprendizagem em cursos online. Cinco estilos de videoaula foram utilizados nesse estudo: estilo tradicional (aula tradicional apresentada em sala de aula); estilo cabeça falante (parte superior do corpo do professor falando para a câmera), estilo voz, imagem e apresentação (imagem e voz do professor e apresentação de slides); estilo Khan (voz com escrita e desenho manual em quadro eletrônico); estilo tutorial (voz e demonstração passo a passo de uma tarefa em um software). O nome Khan é devido ao estilo ter sido popularizado pela Khan Academy (fundada por Salman Khan). De acordo com as interações dos alunos registradas em arquivos de $\log$, o estilo considerado mais envolvente foi o estilo tutorial (os alunos pausam o vídeo, executam ações e depois continuam a assistir o vídeo). Adicionalmente, são conclusões desse estudo que as videoaulas que intercalam estilo cabeça falante com apresentação de slides são mais atraentes e videoaulas no estilo tutorial envolvem mais do que somente a apresentação de slides.

Cross et al. (2013) realizaram um experimento controlado para avaliar a preferência do aluno com relação a dois estilos de videoaula: escrita e desenho manual em um quadro eletrônico (estilo Khan) e escrita digital, datilografada, em apresentação com o PowerPoint. Como a preferência pelo estilo de videoaula não teve uma variação significativa, um novo estilo para videoaula foi definido, chamado de TypeRighting, no qual as palavras são escritas manualmente e na sequência se transformam em escrita datilografada. Ao disponibilizar um vídeo desenvolvido no estilo TypeRighting e nos outros dois estilos, os resultados de entrevistas mostram uma preferência significativa para o estilo TypeRighting. 
Dotta et al. (2013) tiveram como objetivo principal analisar as preferências de alunos no uso de videoaulas. As videoaulas desse estudo foram produzidas com a captura da imagem e áudio do professor durante a apresentação de slides, a captura posterior somente da apresentação de slides de acordo com o áudio gravado na etapa anterior, e edição dos itens produzidos nas etapas anteriores para sincronização e adição de elementos de animação. Por meio de um questionário foi identificado que os alunos têm preferência pelo aparecimento da imagem do professor e não somente da sua narração. Outra preferência identificada é pela utilização de animações.

O objetivo do trabalho de Ilioudi et al. (2013) foi definir qual a melhor abordagem para o ensino de matemática no ensino médio. Dois vídeos foram criados, um no estilo cabeça falante com auxílio do quadro negro e o outro no estilo Khan, e cada vídeo com o objetivo de ensinar três módulos predefinidos de matemática. O livro tradicional foi utilizado como uma terceira abordagem de ensino. As abordagens foram aplicadas para grupos de alunos para definir qual estilo de videoaula causava mais impacto. A abordagem que causou maior impacto na aprendizagem foi o estilo cabeça falante (com quadro negro).

Vieira et al. (2014) tiveram como objetivo desenvolver videoaulas de matemática com possibilidade de maior interação e envolvimento para universitários de cursos online. A decisão foi utilizar o estilo voz e apresentação depois de também analisar outros estilos presentes em videoaulas como o estilo tradicional, cabeça falante e estilo interativo (videoaula com diversos recursos interativos como exercícios e animações). Vieira et al. concluíram que é importante promover a interação do aluno com a videoaula. Além disso, também é preciso produzir videoaulas curtas, evitar transições bruscas e oferecer links interativos.

O objetivo de Brecht (2012) foi comparar os resultados de projetos alternativos de videoaula (entre outros objetivos relacionados à aceitação e eficácia de videoaulas). Brecht testou três projetos de videoaula: (a) com completa ausência de atenção para elementos de mudança de ritmo (estilo tradicional); (b) com gráficos animados e sons musicais, apresentados para propiciar alívio de cansaço durante o estudo (estilo voz e apresentação com recursos interativos); (c) com poucos gráficos e sons sutilmente apresentados de forma que não extraíssem toda a atenção dos alunos (estilo voz e apresentação). Os estudantes apresentaram melhor desempenho com o projeto (b) e os resultados para o projeto (a) diferem significativamente dos projetos (b) e (c).

$\mathrm{Na}$ Tabela 1 é apresentada uma comparação entre os trabalhos sobre estilos de videoaula. Alguns dos trabalhos encontrados na literatura têm como objetivo verificar se os estilos podem interferir no processo ensino-aprendizagem, enquanto outros visam identificar quais estilos levam aos melhores resultados de aprendizagem. No entanto, pouco é explorado quanto à preferência dos estilos com relação ao uso pelos alunos e à produção pelos docentes.

\section{Metodologia}

O método usado neste trabalho para auxiliar a identificação de requisitos de software foi o levantamento (survey). Análise ou Elicitação de Requisitos consiste na identificação dos requisitos necessários à implementação de um sistema (Sommerville e Kotonya 1998). Além do levantamento, outros métodos também podem ser utilizados na 
identificação de requisitos, por exemplo, criação de cenários e protótipos, realização de entrevistas e brainstorming. Um levantamento é conduzido por meio do uso de instrumentos que permitem medir ou descrever o problema investigado (Malheiros 2011). Neste trabalho, a técnica de questionário foi utilizada no levantamento para a coleta de dados.

O levantamento foi realizado em cinco etapas: (1) elaboração do instrumento de coleta de dados (questionários); (2) pré-teste dos questionários; (3) seleção da amostra; (4) aplicação dos questionários; e (5) análise e interpretação dos dados. Os questionários (diferentes para alunos e professores) foram elaborados com questões de múltipla escolha, questões em escala Likert de sete pontos e questões abertas. O questionário para alunos é dividido em três seções: caracterização do respondente; preferências com relação à videoaula; e concordância com declarações sobre utilização de videoaula. $O$ questionário para docentes tem essas três seções mais uma seção de preferências com relação à produção de videoaula.

Os estilos de videoaula considerados neste estudo foram os seguintes: tradicional; cabeça falante; voz e apresentação; imagem, voz e apresentação; Khan; e tutorial. Esse conjunto consiste nos estilos descritos por Guo et al. (2014) acrescido do estilo voz e apresentação, uma variante do estilo imagem, voz e apresentação (sem a imagem do professor). Além de questões relacionadas a videoaula em geral e estilos de videoaula, o uso de recursos interativos (como animações interativas e links para página da Web ou material adicional) também foi investigado neste estudo. A lista de recursos interativos considerada foi obtida a partir do estudo de ferramentas de produção de videoaulas. Especificamente para os professores, o estudo abrangeu também questões sobre conhecimento de metodologias e técnicas de produção de videoaulas e preferência por determinadas ferramentas específicas para produção de videoaulas.

Tabela 1. Comparação entre os trabalhos sobre estilos de videoaula

\begin{tabular}{|c|c|c|c|}
\hline TRABALHO & ESTILOS & PREFERÊNCIA & PRODUÇÃO \\
\hline Guo et al. (2014) & $\begin{array}{l}\text { - Tradicional; } \\
\text { - Cabeça falante; } \\
\text { - Voz, imagem e } \\
\text { apresentação; } \\
\text { - Khan; } \\
\text { - Tutorial. }\end{array}$ & $\begin{array}{l}\text { - Estilo voz e apresentação e } \\
\text { estilo tutorial. }\end{array}$ & $\begin{array}{l}\text { - Pré-produção; } \\
\text { - Produção; } \\
\text { - Pós-produção. }\end{array}$ \\
\hline Cross et al. (2013) & $\begin{array}{l}\text { - Khan; } \\
\text { - Voz e apresentação; } \\
\text { - TypeRighting. }\end{array}$ & $\begin{array}{l}\text { - Não houve variância } \\
\text { significativa nos estilos Khan } \\
\text { e voz e apresentação; } \\
\text { - TypeRighting. }\end{array}$ & - Não apresenta. \\
\hline Dotta et al. (2013) & $\begin{array}{l}\text { - Voz, imagem e } \\
\text { apresentação. }\end{array}$ & $\begin{array}{l}\text { - Uso da imagem do professor } \\
\text { e de animação. }\end{array}$ & $\begin{array}{l}\text { - Roteiro de } \\
\text { produção. }\end{array}$ \\
\hline llioudi et al. (2013) & $\begin{array}{l}\text { - Cabeça falante (com } \\
\text { quadro negro); } \\
\text { - Khan. }\end{array}$ & $\begin{array}{l}\text { Cabeça falante (com quadro } \\
\text { negro). }\end{array}$ & - Não apresenta. \\
\hline Vieira et al. (2014) & $\begin{array}{l}\text { - Tradicional; } \\
\text { - Cabeça falante; } \\
\text { - Voz e apresentação; } \\
\text { - Interativo. }\end{array}$ & - Voz e apresentação. & - Não apresenta. \\
\hline Brecht (2012) & $\begin{array}{l}\text { - Tradicional; } \\
\text { - Voz e apresentação com } \\
\text { gráficos animados e sons } \\
\text { musicais; } \\
\text { - Voz e apresentação com } \\
\text { poucos gráficos e sons. }\end{array}$ & $\begin{array}{l}\text { - Voz e apresentação com } \\
\text { gráficos animados e sons } \\
\text { musicais. }\end{array}$ & $\begin{array}{l}\text { - O projeto } \\
\text { seguinte foi } \\
\text { criado após o } \\
\text { projeto anterior } \\
\text { ser testado. }\end{array}$ \\
\hline
\end{tabular}


No pré-teste realizado, o questionário para alunos foi aplicado a 18 respondentes e o questionário para professores foi aplicado a 10 respondentes. De 10 a 20 respondentes são suficientes para validar o instrumento independentemente do tamanho da amostra (Grossman et al. 2009). O pré-teste é considerado um estudo piloto conduzido antes da aplicação do questionário para fornecer subsídios para melhorar a versão final do questionário. Os resultados do pré-teste foram utilizados para simular a análise e interpretação dos dados. $\mathrm{O}$ respondente do pré-teste também pôde fornecer uma opinião por meio de uma questão aberta sobre a qualidade das questões e sugerir alguma melhoria. No pré-teste do questionário para alunos houve um comentário sobre uma questão com resposta múltipla exigir a seleção de pelo menos três alternativas; após análise, essa restrição foi removida. Nenhum respondente do pré-teste informou qualquer outra dificuldade em responder as questões.

O questionário foi enviado a 446 alunos e 49 professores dos cursos técnicos (subsequentes ao ensino médio) em Redes de Computadores, em Eletrônica e em Manutenção e Suporte em Informática, Modalidade a Distância, da Escola Técnica Aberta do Brasil (e-Tec Brasil). A amostra foi determinada usando o critério de amostragem não probabilística por conveniência. A mensagem para os respondentes incluiu um link para a página do questionário online que esteve disponível por 51 dias e recebeu 97 respostas de alunos e 39 respostas de professores (que corresponde a uma taxa de resposta de $21,7 \%$ e $79,5 \%$, respectivamente). Os dados foram formatados em uma planilha e importados para uma ferramenta estatística para facilitar a análise. A análise foi realizada por meio de análise estatística descritiva.

\section{Resultados e Discussão}

Nesta seção são apresentadas a caracterização e as preferências dos respondentes. A comparação entre alunos e professores é discutida ao apresentar as preferências dos professores.

\subsection{Caracterização dos Respondentes}

Do total de respondentes (alunos) matriculados em um curso técnico do e-Tec Brasil, $88,7 \%$ são homens e $48,5 \%$ possuem entre 21 e 30 anos (20,6\% possuem entre 31 e 40 anos, $15,5 \%$ com mais de 40 anos e 15,5\% possuem entre 18 e 20 anos). Os respondentes confirmaram que já utilizaram videoaulas para o aprendizado de um conteúdo, sejam videoaulas pesquisadas na Internet $(69,1 \%)$, disponibilizadas pelo professor $(63,9 \%)$ ou indicadas por colegas $(30,9 \%)$. Além disso, os respondentes também já utilizaram diferentes estilos, principalmente o estilo tutorial (66\%), voz e apresentação $(55,7 \%)$, imagem, voz e apresentação $(51,5 \%)$, Khan $(43,3 \%)$, tradicional $(43,3 \%)$ e o estilo cabeça falante $(38,1 \%)$. Quanto a recursos interativos, os alunos já experimentaram diversos tipos, principalmente download de material adicional $(68 \%)$, pausa/reprodução $(54,6 \%)$, página da Web $(45,4 \%)$, avanço/recuo rápido $(41,2 \%)$, respostas a perguntas (34\%) e dicas de estudo (34\%).

Com relação aos professores, todos ministraram ou estão ministrando disciplinas no âmbito do e-Tec Brasil. Do total de respondentes (professores), 74,4\% são homens e $38,5 \%$ possuem entre 31 e 40 anos (30,8\% entre 41 e 50 anos, 7,7\% entre 20 e 30 anos e $23 \%$ mais de 50 anos). Entre os respondentes, $41 \%$ são doutores, $46,2 \%$ são mestres e 
$12,8 \%$ são especialistas; 53,8\% atuam na carreira há mais de 16 anos (com 35,8\% entre 6 e 15 anos e 10,3\% entre 1 e 5 anos); a área de formação é diversificada: ciência da computação, línguas, engenharia elétrica/eletrônica e administração.

Os respondentes (professores) confirmaram que já utilizaram videoaulas para o ensino de um conteúdo, sejam videoaulas produzidas pelos próprios professores $(84,6 \%)$, disponibilizadas por colegas $(35,9 \%)$ ou pesquisadas na Internet $(30,8 \%)$. Além disso, os respondentes também já utilizaram diferentes estilos, principalmente o estilo voz e apresentação (69,2\%), tutorial $(53,8 \%)$, imagem, voz e apresentação $(48,7 \%)$, cabeça falante $(41 \%)$, Khan $(33,3 \%)$, e estilo tradicional $(30,8 \%)$. Quanto a recursos interativos, os respondentes já utilizaram diversos tipos em suas videoaulas, principalmente download de material adicional (59\%), exemplo prático $(48,7 \%)$, dicas de estudo (48,7\%), pausa/reprodução $(48,7 \%)$, página da Web $(41 \%)$ e exercício complementar $(38,5 \%)$.

\subsection{Preferências dos Alunos}

Os respondentes selecionaram os estilos de videoaula que preferem utilizar para o aprendizado de um conteúdo em uma questão de múltipla escolha (resposta múltipla); o resultado é apresentado na Tabela 2. A preferência dos alunos pelo estilo tutorial pode estar relacionada com a natureza técnica do conteúdo das disciplinas, que precisam repetidamente de apresentações de "como fazer" e o estilo tutorial atende essa demanda. A preferência de alunos pelo estilo tutorial também foi identificada por Guo et al. (2014).

Tabela 2. Preferências dos alunos com relação aos estilos de videoaula

\begin{tabular}{|l|c|c|}
\hline \multicolumn{1}{|c|}{ Estilos de videoaula } & \multicolumn{2}{c|}{ Frequência } \\
\hline Estilo tutorial & 57 & $58,8 \%$ \\
\hline Estilo imagem, voz e apresentação & 52 & $53,6 \%$ \\
\hline Estilo Khan & 40 & $41,2 \%$ \\
\hline Estilo tradicional & 36 & $37,1 \%$ \\
\hline Estilo voz e apresentação & 30 & $30,9 \%$ \\
\hline Estilo cabeça falante & 23 & $23,7 \%$ \\
\hline Não tenho preferência & 08 & $8,2 \%$ \\
\hline
\end{tabular}

Os alunos têm preferência por videoaulas curtas, pois quando perguntados sobre qual o tempo médio de duração deveria ter uma videoaula, as respostas foram: até 10 min. (10,3\%), de 11 a $20 \mathrm{~min}$. (35,1\%), de 21 a $40 \mathrm{~min}$. (30,9\%), de 41 a $60 \mathrm{~min}$. $(16,5 \%)$ e acima de $61 \mathrm{~min}$. (6,2\%). A necessidade de oferecer videoaulas curtas aos alunos é ressaltada por Dotta et al. (2013), Guo et al. (2014) e Vieira et al. (2014).

Os respondentes selecionaram os recursos interativos que preferem (ou gostariam de) utilizar em videoaulas por meio de uma questão de múltipla escolha (resposta múltipla); o resultado é apresentado na Tabela 3. A preferência pelo download de material adicional pode estar relacionada à necessidade de complementar a aprendizagem do conteúdo. A preferência pelo exemplo prático também pode estar relacionada à natureza técnica do conteúdo das disciplinas. Adicionalmente, $85,6 \%$ dos respondentes afirmaram que gostariam de utilizar mais recursos interativos em videoaulas. Nesse sentido, Vieira et al. (2014) ressalta a importância de promover a interação do aluno com a videoaula. 
CBIE-LACLO 2015

Anais do XXVI Simpósio Brasileiro de Informática na Educação (SBIE 2015)

Tabela 3. Preferências dos alunos com relação aos recursos interativos

\begin{tabular}{|l|c|c|}
\hline \multicolumn{1}{|c|}{ Recursos interativos } & \multicolumn{2}{c|}{ Frequência } \\
\hline Download de material adicional & 57 & $58,8 \%$ \\
\hline Exemplo prático & 51 & $52,6 \%$ \\
\hline Comunicação com o professor & 45 & $46,4 \%$ \\
\hline Pausa/reprodução & 44 & $44,4 \%$ \\
\hline Dicas de estudo & 42 & $43,3 \%$ \\
\hline Sumário para acesso rápido a trechos da videoaula & 42 & $43,3 \%$ \\
\hline Animação interativa (com escolha de opções ou parâmetros) & 40 & $41,2 \%$ \\
\hline Exercício complementar & 39 & $40,2 \%$ \\
\hline Página da Web (ou website) & 38 & $39,2 \%$ \\
\hline Respostas a perguntas & 34 & $35,1 \%$ \\
\hline Avanço/recuo rápido & 34 & $35,1 \%$ \\
\hline Comunicação com o tutor & 30 & $30,9 \%$ \\
\hline Repetição de trechos da videoaula & 30 & $30,9 \%$ \\
\hline Avaliação ou comentários (feedback) & 30 & $30,9 \%$ \\
\hline Pergunta de acompanhamento & 27 & $27,8 \%$ \\
\hline Enquete (pesquisa informal de opinião) & 22 & $22,7 \%$ \\
\hline Nenhum & 05 & $5,2 \%$ \\
\hline
\end{tabular}

Os respondentes expressaram o seu nível de concordância a respeito de afirmações sobre videoaula por meio de questões em escala Likert de sete pontos (de 1, discordo totalmente, a 7, concordo totalmente) e o resultado é apresentado na Tabela 4. As afirmações 1, 3 e 4 foram as de maior concordância, considerando que a maioria dos respondentes expressou 6 ou 7 (69\%, 58,8\% e 57,7\% dos respondentes, respectivamente para as afirmações 1, 3 e 4; mediana 6 e moda 7 para as três afirmações). Além disso, um aspecto interessante é a divergência de opinião dos alunos quanto ao tempo empregado para assistir uma videoaula ser considerado um aspecto negativo (afirmação 5). Essa questão merece ser investigada com mais profundidade.

Tabela 4. Resultados para as questões em escala Likert sobre videoaula

\begin{tabular}{|l|c|c|c|c|c|c|c|c|c|}
\hline \multicolumn{7}{|c|}{ Afirmação } & \multicolumn{7}{c|}{ Frequência (\%) } & \multirow{2}{*}{ Med. } & Moda \\
\cline { 2 - 11 } & $\mathbf{1}$ & $\mathbf{2}$ & $\mathbf{3}$ & $\mathbf{4}$ & $\mathbf{5}$ & $\mathbf{6}$ & $\mathbf{7}$ & & \\
\hline $\begin{array}{l}\text { 1. O estilo da videoaula pode } \\
\text { interferir na aprendizagem do } \\
\text { conteúdo }\end{array}$ & 1,0 & - & 1,0 & 13,4 & 15,5 & 21,6 & 47,4 & 6 & 7 \\
\hline $\begin{array}{l}\text { 2. A videoaula em que o professor } \\
\text { fala rápido e com grande } \\
\text { entusiasmo é mais envolvente }\end{array}$ & 6,2 & 6,2 & 11,3 & 19,6 & 20,6 & 12,4 & 23,7 & 5 & 7 \\
\hline $\begin{array}{l}\text { 3. A videoaula em que o professor } \\
\text { fala de forma compassada facilita o } \\
\text { entendimento }\end{array}$ & 2,1 & 3,1 & 6,2 & 14,4 & 15,5 & 15,5 & 43,3 & 6 & 7 \\
\hline $\begin{array}{l}\text { 4. A videoaula que intercala a } \\
\text { imagem do professor com slides é } \\
\text { mais atraente }\end{array}$ & 2,1 & 8,2 & 6,2 & 9,3 & 16,5 & 24,7 & 33,0 & 6 & 7 \\
\hline $\begin{array}{l}5 . \text { O tempo empregado para assistir } \\
\text { uma videoaula é um aspecto } \\
\text { negativo na sua utilização }\end{array}$ & 16,5 & 16,5 & 13,4 & 22,7 & 7,2 & 7,2 & 16,5 & 4 & 4 \\
\hline
\end{tabular}

\subsection{Preferências dos Professores}

Os respondentes selecionaram os estilos de videoaula que preferem produzir para o ensino de um conteúdo em uma questão de múltipla escolha (resposta múltipla); o resultado é apresentado na Tabela 5. Os respondentes preferem produzir os estilos voz e apresentação e imagem, voz e apresentação. Por um lado, existe um conflito com a preferência dos alunos (tutorial); por outro lado, 30,9\% dos alunos também preferem o estilo voz e apresentação e (53,6\%) preferem o estilo imagem, voz e apresentação. 
Os respondentes têm preferência por videoaulas curtas, pois quando perguntados sobre qual o tempo médio de duração deveria ter uma videoaula, as respostas foram: até $10 \mathrm{~min}$. (15,4\%), de 11 a $20 \mathrm{~min}$. (38,5\%), de 21 a $40 \mathrm{~min}$. (30,8\%), de 41 a $60 \mathrm{~min}$. $(12,8 \%)$ e acima de 61 min. (2,6\%). Essa preferência está em harmonia com a dos alunos e trabalhos da literatura (Dotta et al. 2013; Guo et al. 2014; Vieira et al. 2014).

Tabela 5. Preferências dos professores com relação aos estilos de videoaula

\begin{tabular}{|l|c|c|}
\hline \multicolumn{1}{|c|}{ Estilos de videoaula } & \multicolumn{2}{c|}{ Frequência } \\
\hline Estilo voz e apresentação & 19 & $48,7 \%$ \\
\hline Estilo imagem, voz e apresentação & 17 & $43,6 \%$ \\
\hline Estilo tutorial & 13 & $33,3 \%$ \\
\hline Estilo Khan & 09 & $23,1 \%$ \\
\hline Estilo tradicional & 08 & $20,5 \%$ \\
\hline Estilo cabeça falante & 07 & $17,9 \%$ \\
\hline Não tenho preferência & 04 & $10,3 \%$ \\
\hline
\end{tabular}

Os respondentes selecionaram os recursos interativos que preferem (ou gostariam de) incluir em videoaulas por meio de uma questão de múltipla escolha (resposta múltipla); o resultado é apresentado na Tabela 6. Essa preferência também está em harmonia com a dos alunos, uma vez que exemplo prático e download de material adicional também figuram entre os recursos mais selecionados. Adicionalmente, 89,7\% dos respondentes afirmaram que gostariam de aprender a incluir mais recursos interativos em suas videoaulas.

Tabela 6. Preferências dos professores com relação aos recursos interativos

\begin{tabular}{|l|c|c|}
\hline \multicolumn{1}{|c|}{ Recursos interativos } & \multicolumn{2}{c|}{ Frequência } \\
\hline Exemplo prático & 26 & $66,7 \%$ \\
\hline Página da Web (ou website) & 22 & $56,4 \%$ \\
\hline Dicas de estudo & 21 & $53,8 \%$ \\
\hline Download de material adicional & 21 & $53,8 \%$ \\
\hline Animação interativa (com escolha de opçães ou parâmetros) & 20 & $51,3 \%$ \\
\hline Respostas a perguntas & 19 & $48,7 \%$ \\
\hline Sumário para acesso rápido a trechos da videoaula & 18 & $46,2 \%$ \\
\hline Exercício complementar & 18 & $46,2 \%$ \\
\hline Pergunta de acompanhamento & 18 & $46,2 \%$ \\
\hline Comunicação com o professor & 16 & $41,0 \%$ \\
\hline Avaliação ou comentários (feedback) & 16 & $41,0 \%$ \\
\hline Pausa/reprodução & 15 & $38,5 \%$ \\
\hline Avanço/recuo rápido & 14 & $35,9 \%$ \\
\hline Comunicação com o tutor & 11 & $28,2 \%$ \\
\hline Repetição de trechos da videoaula & 09 & $23,1 \%$ \\
\hline Enquete (pesquisa informal de opinião) & 09 & $23,1 \%$ \\
\hline Nenhum & 02 & $5,1 \%$ \\
\hline
\end{tabular}

As foram as seguintes: apresentação de conteúdo que excede o tempo de aula; necessidade específica de cursos na modalidade à distância; e indisponibilidade de videoaulas relacionadas a conteúdo técnico específico. No entanto, a frequência com que os respondentes produzem videoaulas é baixa, pois apenas 20,5\% responderam sempre ou frequentemente (com $35,8 \%$ às vezes e $35,9 \%$ raramente).

Ainda com relação à produção de videoaula, a maioria dos respondentes expressou na resposta a uma questão aberta que não conhecem alguma metodologia ou técnica para a produção de videoaula. No entanto, $87,2 \%$ dos respondentes possuem predisposição para aprender novas metodologias e técnicas para a produção de videoaula. As principais ferramentas utilizadas são Camtasia Studio $(61,5 \%)$ e Windows Movie Maker (43,6\%); 15,4\% dos respondentes indicaram que não utilizam ferramentas 
específicas (dependem de outras pessoas para produzir as suas videoaulas) e $87,2 \%$ dos respondentes gostariam de aprender novas ferramentas para a produção de videoaulas.

Os respondentes expressaram o seu nível de concordância a respeito de afirmações sobre videoaula e o resultado é apresentado na Tabela 7. De maneira semelhante aos alunos, a maioria dos professores também expressaram 6 ou 7 para as afirmações 1, 3 e 4 (mediana 6 e moda 7). Para a afirmação 6 (pergunta adicional no questionário dos professores), 61,6\% expressaram 6 ou 7 (mediana e moda igual a 7). Esse último resultado indica necessidade de capacitação dos professores no uso de ferramentas para a produção de videoaula.

Tabela 7. Resultados para as questões em escala Likert sobre videoaula

\begin{tabular}{|c|c|c|c|c|c|c|c|c|c|}
\hline \multirow{2}{*}{ Afirmação } & \multicolumn{7}{|c|}{ Frequência (\%) } & \multirow{2}{*}{ Med. } & \multirow{2}{*}{ Moda } \\
\hline & 1 & 2 & 3 & 4 & 5 & 6 & 7 & & \\
\hline $\begin{array}{l}\text { 1. O estilo da videoaula pode } \\
\text { interferir na aprendizagem do } \\
\text { conteúdo }\end{array}$ & - & - & 2,6 & 20,5 & 12,8 & 15,4 & 48,7 & 6 & 7 \\
\hline $\begin{array}{l}\text { 2. A videoaula em que o professor } \\
\text { fala rápido e com grande } \\
\text { entusiasmo é mais envolvente }\end{array}$ & 2,6 & 5,1 & 12,8 & 17,9 & 30,8 & 10,3 & 20,5 & 5 & 5 \\
\hline $\begin{array}{l}\text { 3. A videoaula em que o professor } \\
\text { fala de forma compassada facilita o } \\
\text { entendimento }\end{array}$ & - & 2,6 & 7,7 & 12,8 & 15,4 & 23,1 & 38,5 & 6 & 7 \\
\hline $\begin{array}{l}\text { 4. A videoaula que intercala a } \\
\text { imagem do professor com slides é } \\
\text { mais atraente }\end{array}$ & - & 2,6 & - & 17,9 & 23,1 & 23,1 & 33,3 & 6 & 7 \\
\hline $\begin{array}{l}5 . \text { O tempo empregado na } \\
\text { produção de uma videoaula é um } \\
\text { aspecto negativo na sua utilização }\end{array}$ & 7,7 & 2,6 & 2,6 & 30,8 & 15,4 & 23,1 & 17,9 & 5 & 4 \\
\hline $\begin{array}{l}\text { 6. A inexperiência do professor com } \\
\text { as ferramentas de produção de } \\
\text { videoaula é um aspecto negativo na } \\
\text { sua utilização }\end{array}$ & 7,7 & - & 2,6 & 20,5 & 7,7 & 10,3 & 51,3 & 7 & 7 \\
\hline
\end{tabular}

\section{Conclusão}

O levantamento realizado com alunos e professores de cursos técnicos resultou em dados importantes sobre as preferências com relação à videoaula. Alguns requisitos foram identificados com base nos resultados deste estudo. Assim, uma ferramenta para produção de videoaula deve:

- prover um meio simples de produzir videoaula em diferentes estilos. Por exemplo, fornecendo modelos pré-definidos e esquemas passo a passo (wizards).

- controlar o tempo de duração da videoaula durante a produção. Por exemplo, incluindo um alerta na linha de tempo (timeline) da ferramenta.

- facilitar a inclusão de recursos interativos. Por exemplo, fornecendo uma biblioteca de recursos interativos pré-definidos de fácil configuração.

- analisar a voz do professor na videoaula para indicar necessidade de mudança de ritmo. Por exemplo, realizando uma calibração inicial e análise de áudio depois.

- incluir uma metodologia ou técnica para apoio à produção de videoaula. Por exemplo, permitindo estabelecer a sequência didático-pedagógica da videoaula ou ainda a modelagem prévia do domínio. 
Os resultados obtidos também são importantes para outros contextos. Por exemplo, um programa de treinamento de professores na produção de videoaula deveria reforçar os estilos de preferência dos alunos, incentivar o uso de recursos interativos, incluir alguma metodologia ou técnica de produção e adotar ferramentas de preferência dos professores.

\section{Referências}

Barrére, E., Scortegagna, L. and Lélis, C. A. S. (2011) Produção de Videoaulas para o serviço EDAD da RNP. In: Anais do XXII SBIE - XVII WIE, Aracajú, p. 284-293.

Brecht, H. D. (2012) Learning from online video lectures. Journal of Information Technology Education: Innovations in Practice, v. 11, p. 227-250.

Chandra, S. (2011) Experiences in personal lecture video capture. IEEE Transactions on Learning Technologies, v. 4, n. 3, p. 261-274.

Cross, A., Bayyapunedi, M., Cutrell, E., Agarwal, A. and Thies, W. (2013) TypeRighting: combining the benefits of handwriting and typeface in online educational videos. In: Proc. of the SIGCHI Conf. on Human Factors in Computing Systems, France, p. 793-796.

Dotta, S. C., Jorge, E. C., Pimentel, E. P. and Braga, J. C. (2013) Análise das Preferências dos Estudantes no uso de Videoaulas: Uma experiência na Educação a Distância. In: Anais do II CBIE - XIX WIE, Campinas, p. 21-30.

Grossman, T., Fitzmaurice, G. and Attar, R. (2009) A Survey of Software Learnability: Metrics, Methodologies and Guidelines. In: Proc. of the SIGCHI Conference on Human Factors in Computing Systems, Boston, p. 649-658.

Guo, P. J., Kim, J. and Rubin, R. (2014) How video production affects student engagement: an empirical study of MOOC videos. In: Proc. of the 1st ACM Conference on Learning at Scale, Atlanta, p 41-50.

Ilioudi, C., Giannakos, M. N. and Chorianopoulos, K. (2013) Investigating Differences among the Commonly Used Video Lecture Styles. In: Proc. of the Workshop on Analytics on Video-based Learning, Leuven, p. 21-26.

Keengwe, J. (2007) Faculty integration of technology into instruction and students' perceptions of computer technology to improve student learning. Journal of Information Technology Education, v. 6, p. 169-180.

Malheiros, B. T. Metodologia da Pesquisa em Educação. Rio de Janeiro: LTC, 2011.

Raabe, A., Bernardes, A. and Augusto Junior, R. G. (2014) Produção e Avaliação de Videoaulas: Um Estudo de Caso no Ensino de Programação. In: Anais do XXV SBIE - XX WIE, Dourados, p. 448-456.

Sommerville, I. and Kotonya, G. (1998) Requirements Engineering: Processes and Techniques. New York, John Wiley \& Sons.

Vieira, I., Lopes, A. P. and Soares, F. (2014) The potential benefits of using videos in higher education. In: Proc. of the 6th International Conference on Education and New Technologies, Barcelona, p. 750-756. 